\title{
Effects of Entropy Generation, Thermal Radiation and Moving-Wall Direction on Mixed Convective Flow of Nanofluid in an Enclosure
}

\author{
Sivasankaran Sivanandam ${ }^{1, *(1)}$, Ali J. Chamkha ${ }^{2,3}$, Fouad O. M. Mallawi ${ }^{1}$, Metib S. Alghamdi ${ }^{4}$ \\ and Aisha M. Alqahtani ${ }^{5}$ \\ 1 Department of Mathematics, King Abdulaziz University, Jeddah 21589, Saudi Arabia; fmallawi@hotmail.com \\ 2 Institute of Research and Development, Duy Tan University, Da Nang 550000, Vietnam; \\ alichamkha@duytan.edu.vn \\ 3 Institute of Theoretical and Applied Research (ITAR), Duy Tan University, Hanoi 100000, Vietnam \\ 4 Mathematics Department, King Khalid University, Abha 61421, Saudi Arabia; dr.matabalghamdi@gmail.com \\ 5 Mathematics Department, Princess Nourah bint Abdulrahman University, Riyadh 84428, Saudi Arabia; \\ aalqahtani@gmail.com \\ * Correspondence: smsivanandam@kau.edu.sa or sd.siva@yahoo.com
}

Received: 16 July 2020; Accepted: 27 August 2020; Published: 1 September 2020

\begin{abstract}
A numeric investigation is executed to understand the impact of moving-wall direction, thermal radiation, entropy generation and nanofluid volume fraction on combined convection and energy transfer of nanoliquids in a differential heated box. The top wall of the enclosed box is assumed to move either to the left or the right direction which affects the stream inside the box. The horizontal barriers are engaged to be adiabatic. The derived mathematical model is solved by the control volume technique. The results are presented graphically to know the impact of the dissimilar ways of moving wall, Richardson number, Bejan number, thermal radiation, cup mixing and average temperatures. It is concluded that the stream and the thermal distribution are intensely affected by the moving-wall direction. It is established that the thermal radiation enhances the convection energy transport inside the enclosure.
\end{abstract}

Keywords: mixed convection; thermal radiation; entropy; nanoliquid; moving wall

\section{Introduction}

The combined convective movement and thermal energy transfer have been examined in a huge number of studies for decades because of its applications in numerous fields of technological sciences. Since the communal interaction among the viscous, buoyancy, and inertia forces on the stream has been a vital matter for joint convection in a lid-driven enclosed box, the moving wall's direction of the cavity becomes significant in these studies [1-4]. Therefore, the current work keenly involves the influence of moving-wall direction on convective stream in lid-driven cavities. Combined convection together with heat transfer have been examined under several conditions in enormous studies [5-9]. Sivasankaran et al. [10] numerically explored the mixed convective stream and the energy transport in an inclined enclosed space with discrete heating. Sivasankaran and Pan [11] discovered the influence of discrete heaters and coolers on convection in a closed box. Mekroussi et al. [12] explored the combined convection in a top-driven inclined wavy walled box. Combined convection flow due to nonuniform heating in an enclosed box is discovered in some studies [13-15].

Nanofluids are pioneering fluids in the field of thermal science and it has been used actively to analyze the energy transport in thermal systems [16-22]. Sheremet et al. [21] discovered the buoyant flow and entropy generation of nanoliquid in a closed box with variable border temperature. 
Alsabery et al. [22] numerically explored the entropy generation and convection of nanoliquid in a wavy walled box. Santra et al. [23] deliberated the energy transfer augmentation of a water-copper nanoliquid in a differentially heated box. Abu-Nada and Oztop [24] discovered the outcome of inclination of the box on convection of a $\mathrm{Cu}$-water nanofluid. Ghasemi and Aminossadati [25] explored the buoyant convection of a $\mathrm{CuO}$ nanoliquid in an inclined box numerically. Bhuvaneswari et al. [26] completed a numeric work to get the impact of variable liquid properties on convective stream of a nanoliquid in a square box. Sivasankaran et al. [27] inspected the partial slip influence on magneto-convection in a 2-sided wall-driven porous enclosed space filled with a $\mathrm{Cu}$-water nanoliquid. Rashad et al. [28] discovered the magneto-convection of heat generating nanoliquids in a trapezoidal box with discrete heating.

The interaction connecting natural/mixed convection and thermal radiation has gained significant consideration due to its uses in various arenas. Very few studies on the interaction of thermal radiation and convective stream have been reported in the literature [29-34]. Mansour et al. [29] discovered the outcome of radiation on buoyant convection in a porous wavy enclosed space using the non-equilibrium thermal model. They found that average heat transport decreased by increasing the surface waviness of the wall. The doubly diffusive convection with radiation in an enclosed box was explored by Moufekkir et al. [30]. Mahapatra et al. [31] explored the influence of heat generation and thermal radiation on magneto-convective stream in an inclined enclosed space with one hot side and chilled from the adjacent side. They concluded that the direction of the magnetic field influenced much on the stream pattern. Saleem et al. [32] scrutinized the impact of radiation on buoyant convection in an open box. They demonstrated that radiative heat transport increased as the optical thickness of the liquid increased. Zhang et al. [33] explored the effects of thermal radiation on magneto-convection in a cavity.

Since no study on combined convection of a nanoliquid in a wall-driven box with thermal radiation and entropy generation is reported in the literature, the current investigation is interested to investigate numerically the effect of entropy, thermal radiation and the direction of wall movement of an enclosed box on the convective stream and energy transfer of a nanoliquid.

\section{Mathematical Modeling}

The physical model displayed in Figure 1 is a 2-dimensional square enclosed box of size $L$ packed with a water-based $\mathrm{Al}_{2} \mathrm{O}_{3}$-nanofluid. The stream is unsteady, incompressible and laminar. The velocity components $(\mathrm{u}, \mathrm{v})$ in Cartesian coordinates $(\mathrm{x}, \mathrm{y})$ are pointed to in Figure 1. The vertical walls of the enclosed domain have uniform temperature distributions. The horizontal barriers are thermally insulated. The gravity performances in the opposite of $y$-direction. The nanoliquid in the enclosed box is considered as a dilute liquid-solid mixture with a constant volume fraction of nanosized particles $\left(\mathrm{Al}_{2} \mathrm{O}_{3}\right)$ distributed within the water. The nanoparticles and water are in thermal-equilibrium. The nanoliquid properties are presumed to be constant, except the density. The linear variation of density (with temperature) is given as $\rho=\rho_{0}\left[1-\beta\left(\theta-\theta_{0}\right)\right]$, where $\beta$ being the quantity of thermal expansion (Boussinesq approximation), $\theta$ is temperature and $\rho_{0}$ is density at reference. The viscous dissipation is discounted here. The mathematical model for conservation of quantities is:

$$
\begin{gathered}
\frac{\partial u}{\partial x}+\frac{\partial v}{\partial y}=0 \\
\frac{\partial u}{\partial t}+u \frac{\partial u}{\partial x}+v \frac{\partial u}{\partial y}=-\frac{1}{\rho_{n f}} \frac{\partial p}{\partial x}+\frac{\mu_{n f}}{\rho_{n f}}\left(\frac{\partial^{2} u}{\partial x^{2}}+\frac{\partial^{2} u}{\partial y^{2}}\right) \\
\frac{\partial v}{\partial t}+u \frac{\partial v}{\partial x}+v \frac{\partial v}{\partial y}=-\frac{1}{\rho_{n f}} \frac{\partial p}{\partial y}+\frac{\mu_{n f}}{\rho_{n f}}\left(\frac{\partial^{2} v}{\partial x^{2}}+\frac{\partial^{2} v}{\partial y^{2}}\right)+\frac{(\rho \beta)_{n f}}{\rho_{n f}} g\left(\theta-\theta_{0}\right) \\
\frac{\partial \theta}{\partial t}+u \frac{\partial \theta}{\partial x}+v \frac{\partial \theta}{\partial y}=\alpha_{n f}\left(\frac{\partial^{2} \theta}{\partial x^{2}}+\frac{\partial^{2} \theta}{\partial y^{2}}\right)+\frac{1}{\left(\rho c_{p}\right)_{n f}}\left(\frac{\partial q_{r}}{\partial x}+\frac{\partial q_{r}}{\partial y}\right)
\end{gathered}
$$




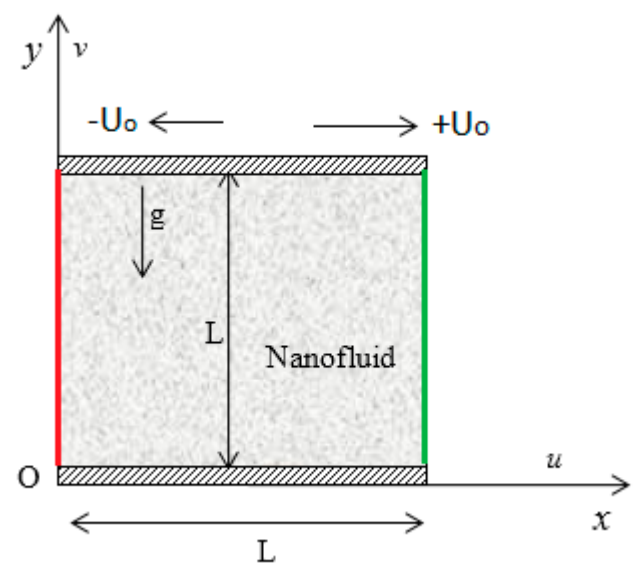

Figure 1. Physical model.

The subscript " $\mathrm{nf}$ " and " 0 " denote the nanofluid and reference state, respectively. The parameters $c_{p}, g, p, t, \alpha, \mu$ are specific heat, acceleration due to gravity, pressure, time, thermal diffusivity and the dynamic viscosity, respectively. The heat flux due to radiation along the $\mathrm{x}$ and $\mathrm{y}$ directions are set by $q r_{x}=\frac{-4 \sigma^{*}}{3 K^{\prime}} \frac{\partial \theta^{4}}{\partial x}$ and $q r_{y}=\frac{-4 \sigma^{*}}{3 K^{\prime}} \frac{\partial \theta^{4}}{\partial y}$, where $\sigma^{*}$ is Stefan-Boltzmann constant and $K^{\prime}$ is mean absorption coefficient. By Rosseland estimate for radiation (medium is optically thick), the thermal variances within the stream are reflected to be too small. Expanding $\theta^{4}$ about $\theta_{0}$ through Taylor series and neglecting the higher order terms obtained from Taylor series, $\theta^{4}$ is expressed as a function of temperature $\theta$. That is,

$$
\theta^{4}=\theta_{0}^{4}+4 \theta_{0}^{3}\left(\theta-\theta_{0}\right)+\ldots
$$

Then, by approximating we get,

$$
\theta^{4} \cong 4 \theta_{0}^{3} \theta-3 \theta_{0}^{4}
$$

Therefore, the radiative heat flux reduces to

$$
q r_{x}=\frac{-16 \sigma^{*} \theta_{0}^{3}}{3 K^{\prime}} \frac{\partial \theta}{\partial x} \text { and } q r_{y}=\frac{-16 \sigma^{*} \theta_{0}^{3}}{3 K^{\prime}} \frac{\partial \theta}{\partial y}
$$

Substituting Equation (5) into Equation (4), we get

$$
\frac{\partial \theta}{\partial t}+u \frac{\partial \theta}{\partial x}+v \frac{\partial \theta}{\partial y}=\alpha_{n f}\left(\frac{\partial^{2} \theta}{\partial x^{2}}+\frac{\partial^{2} \theta}{\partial y^{2}}\right)+\frac{1}{\left(\rho c_{p}\right)_{n f}} \frac{-16 \sigma^{*} \theta_{0}^{3}}{3 K^{\prime}}\left(\frac{\partial^{2} \theta}{\partial x^{2}}+\frac{\partial^{2} \theta}{\partial y^{2}}\right)
$$

Initially, the velocity and temperature are zero. When $t>0, u=v=0$ except at top wall and $u=+U_{0}($ Case -1$), u=-U_{0}($ Case -2$), v=0$ on the top wall. For temperature, $\frac{\partial \theta}{\partial y}=0$ on the top and the bottom portions. The right and left walls are lower $\left(\theta=\theta_{c}\right)$ and higher $\left(\theta=\theta_{h}\right)$ temperature.

The properties of the nanoliquid in the current model are defined below.

Density:

$$
\rho_{n f}=\rho_{f}(1-\phi)+\phi \rho_{p}
$$

Thermal expansion coefficient:

$$
(\rho \beta)_{n f}=(\rho \beta)_{f}(1-\phi)+\phi(\rho \beta)_{p}
$$

Specific heat:

$$
\left(\rho c_{p}\right)_{n f}=\left(\rho c_{p}\right)_{f}(1-\phi)+\phi\left(\rho c_{p}\right)_{p}
$$


The Maxwell formula is used for thermal conductivity:

$$
k_{n f}=k_{f}\left[\frac{2+k_{p f}^{*}+2 \phi\left(k_{p f}^{*}-1\right)}{2+k_{p f}^{*}-\phi\left(k_{p f}^{*}-1\right)}\right], k_{p f}^{*}=\frac{k_{p}}{k_{f}}
$$

The dynamic viscosity of nanoliquid (Ho et al. [35]) is calculated as:

$$
\mu_{n f}=\mu_{f}(1-\phi)^{-2.5}
$$

where the subscript " $f$ " and " $p$ " denote base-fluid and nanoparticle, respectively. The physical constants of the water and nanoparticles $\left(\mathrm{Al}_{2} \mathrm{O}_{3}\right)$ are available in Ref [35].

The leading equations are nondimensionalized by using the subsequent variables:

$$
(U, V)=\frac{(u, v)}{U_{0}}, T=\frac{\theta-\theta_{0}}{\Delta \theta},(X, Y)=\frac{(x, y)}{L}, \tau=\frac{t U_{0}}{L}, \cdots \text { and } P=\frac{p}{\rho_{n f} U_{0}^{2}}
$$

The consequent nondimensional model equations are

$$
\begin{gathered}
\frac{\partial U}{\partial X}+\frac{\partial V}{\partial Y}=0 \\
\frac{\partial U}{\partial \tau}+U \frac{\partial U}{\partial X}+V \frac{\partial U}{\partial Y}=-\frac{\partial P}{\partial X}+\left(\frac{\mu_{n f}}{\rho_{n f} v_{f}}\right)\left(\frac{1}{\operatorname{Re}}\right)\left(\frac{\partial^{2} U}{\partial X^{2}}+\frac{\partial^{2} U}{\partial Y^{2}}\right) \\
\frac{\partial V}{\partial \tau}+U \frac{\partial V}{\partial X}+V \frac{\partial V}{\partial Y}=-\frac{\partial P}{\partial Y}+\left(\frac{\mu_{n f}}{\rho_{n f} \alpha_{f}}\right)\left(\frac{1}{\operatorname{Re}}\right)\left(\frac{\partial^{2} V}{\partial X^{2}}+\frac{\partial^{2} V}{\partial Y^{2}}\right)+\frac{(\rho \beta)_{n f}}{\rho_{n f} \beta_{f}} R i T \\
\frac{\partial T}{\partial \tau}+U \frac{\partial T}{\partial X}+V \frac{\partial T}{\partial Y}=\left(\frac{\alpha_{n f}}{\alpha_{f}} \frac{1}{\operatorname{RePr}}\right)\left(1+\frac{4 k_{f}}{3 k_{n f}} R d\right)\left(\frac{\partial^{2} T}{\partial X^{2}}+\frac{\partial^{2} T}{\partial Y^{2}}\right)
\end{gathered}
$$

The nondimensional quantities appearing above are the Grashof number $G r=\left(g \beta_{f} \Delta \theta L^{3}\right) /\left(v_{f}^{2}\right)$, Radiation parameter $R d=\left(4 \sigma^{*} \theta_{0}^{3}\right) /\left(k_{f} K^{\prime}\right)$, Richardson number $R i=G r / \operatorname{Re}^{2}$, Reynolds number $\operatorname{Re}=\left(U_{0} L\right) /\left(v_{f}\right)$ and the Prandtl number $\operatorname{Pr}=v_{f} / \alpha_{f}$. The boundary settings are

$$
\begin{gathered}
U=V=0, X=0,1 \& Y=0 \\
U=+1(\text { Case } 1), \& U=-1(\text { Case } 2), V=0, Y=1 \\
\frac{\partial T}{\partial Y}=0 Y=0 \& 1 \\
T=1 X=0 \& T=0 X=1
\end{gathered}
$$

when $U=+1$ indicates that the wall moves to the right-side and $U=-1$ implies that the wall moves to the left-side in its axis, respectively.

The drag coefficient estimates the total frictional drag exerted on the wall. The drag coefficient along the moving top wall is calculated as $C f_{x}=\left(\frac{\partial U}{\partial Y}\right)_{Y=1}$, respectively. The averaged drag coefficient is calculated as

$$
\overline{C f_{x}}=\int_{0}^{1} C f_{x} d X, \text { respectively. }
$$

The energy transport rate across the enclosed box is a vital parameter in thermal industrial applications. The local Nusselt number alongside the hot barrier of the enclosed box is defined as 
$N u=\left(-\frac{k_{n f}}{k_{f}}\left(1+\frac{4 k_{f}}{3 k_{n f}} R d\right) \frac{\partial T}{\partial X}\right)_{X=0}$. The averaged Nusselt number alongside the heated barrier is expressed as follows:

$$
\overline{N u}=\int_{0}^{1} N u d Y
$$

\section{Cup Mixing Temperature and RMSD}

The temperature of cup mixing is defined to discover the thermal mixing inside the chamber. The velocity weighted average temperature is most appropriate for convection flow than space averaged temperature. The temperature of cup mixing, and averaged temperature based on area are given as [34]

$$
T_{\text {Cup }}=\frac{\iint \hat{V}(X, Y) T(X, Y) d X d Y}{\iint \hat{V}(X, Y) d X d Y}
$$

where $\hat{V}(X, Y)=\sqrt{U^{2}+V^{2}}$ and

$$
T_{a v g}=\frac{\iint T(X, Y) d X d Y}{\iint d X d Y}
$$

The root-mean square deviation (RMSD) is deduced to calculate the degree of temperature uniformity in all considered cases. They are deduced based on temperature of cup mixing and average temperature based on area as follows:

$$
\begin{aligned}
\text { RMSD }_{T_{\text {cup }}} & =\sqrt{\frac{\sum_{i=1}^{N}\left(T_{i}-T_{\text {Cup }}\right)^{2}}{N}} \\
\text { RMSD }_{T_{\text {avg }}} & =\sqrt{\frac{\sum_{i=1}^{N}\left(T_{i}-T_{a v g}\right)^{2}}{N}}
\end{aligned}
$$

The greater values of RMSD point out poorer temperature regularity in the chamber and vice versa. Moreover, RMSD cannot exceed one because the dimensionless temperature differs between zero and one. These parameters are estimated by the gained values of flow and thermal fields in the same computational code.

\section{Entropy Generation}

The buoyance induced convection in a closed chamber discovers significant awareness in thermal engineering applications. However, the practice of entropy generation supports to spot the ideal conditions for many applications. Since the generation of entropy is as a result of the irreversible procedure of transfer of heat and viscosity, generation of entropy can be estimated from the well-known thermal and velocity fields.

The entropy generation is expressed by two quantities, i.e., heat transfer (first term in below equation) and liquid friction (last term in below equation) [18,21,22,34].

$$
S_{G e n}=\frac{k_{n f}}{T_{c}^{2}}\left[\left(\frac{\partial \theta}{\partial x}\right)^{2}+\left(\frac{\partial \theta}{\partial y}\right)^{2}+\left(\frac{16 \sigma^{*} \theta_{0}^{3}}{3 K^{\prime}}\right)\left(\left(\frac{\partial \theta}{\partial x}\right)^{2}+\left(\frac{\partial \theta}{\partial y}\right)^{2}\right)\right]+\left(\frac{\mu_{n f}}{T_{c}}\right)\left\{2\left[\left(\frac{\partial u}{\partial x}\right)^{2}+\left(\frac{\partial v}{\partial y}\right)^{2}\right]+\left(\frac{\partial u}{\partial y}+\frac{\partial v}{\partial x}\right)^{2}\right\}
$$

The dimensionless entropy generation is acquired by using (10)

$$
\begin{gathered}
S_{\text {total }}=S_{\text {heat }}^{*}+S_{\text {fluid }}^{*} \\
S_{\text {heat }}^{*}=\left(\frac{k_{n f}}{k_{f}}\right)\left(1+\frac{4 R d}{3}\right)\left[\left(\frac{\partial T}{\partial X}\right)^{2}+\left(\frac{\partial T}{\partial Y}\right)^{2}\right]
\end{gathered}
$$




$$
S_{\text {fluid }}^{*}=\phi_{2}\left(\frac{\mu_{n f}}{\mu_{f}}\right)\left\{2\left[\left(\frac{\partial U}{\partial X}\right)^{2}+\left(\frac{\partial V}{\partial Y}\right)^{2}\right]+\left(\frac{\partial U}{\partial Y}+\frac{\partial V}{\partial X}\right)^{2}\right\}
$$

where $\phi_{2}=\frac{U_{0}}{\theta_{0} L^{2}}$. The global entropy generation attains by integrating the local entropy production inside the chamber.

$$
S G_{\text {total }}=\int_{V} S_{\text {total }}(X, Y) d A
$$

The local Bejan number states the strength of generation of entropy owing to thermal transference irreversibility. It is derived as

$$
B e_{\text {loc }}=\frac{S_{\text {heat }}^{*}}{S_{\text {total }}}
$$

For any point in the chamber, when $B e_{l o c}>\frac{1}{2}$, the heat transfer irreversibility is dominating. When $B e_{l o c}<\frac{1}{2}$, the liquid friction irreversibility dominates. If $B e_{l o c}=\frac{1}{2}$, the thermal and viscous irreversibilities are equal. The average value of Bejan number demonstrates the relative importance of the thermal energy transfer irreversibility for the entire chamber.

$$
B e=\frac{\int_{A} B e_{l o c}(X, Y) d A}{\int_{A} d A}
$$

\section{Numeric Technique}

The nondimensional Equations (12)-(15) with boundary conditions (16) are solved by the control volume technique with the "SIMPLE algorithm". A nonuniform grid of $122 \times 122$ is taken to investigate the problem. The justification of the numeric code is very essential in the simulation. An internal code is tested against the available results for free convection of nanoliquid in a box [35] and it is shown in Table 1. Second, the problem of combined convection stream in a lid-driven box [36,37] is employed to compare the results of the current code (See Table 2). A good agreement among these results is

\begin{tabular}{|c|c|c|c|}
\hline Ra (Rayleigh Number) & Volume Fraction & $\begin{array}{r}\overline{N u} \\
\text { Ho et al. [35] }\end{array}$ & Present \\
\hline \multirow[b]{2}{*}{$10^{3}$} & 0.01 & 1.129 & 1.137 \\
\hline & 0.04 & 1.199 & 1.205 \\
\hline \multirow{2}{*}{$10^{4}$} & 0.01 & 2.264 & 2.229 \\
\hline & 0.04 & 2.305 & 2.335 \\
\hline \multirow{2}{*}{$10^{5}$} & 0.01 & 4.699 & 4.683 \\
\hline & 0.04 & 4.810 & 4.791 \\
\hline \multirow{2}{*}{$10^{6}$} & 0.01 & 9.165 & 9.170 \\
\hline & 0.04 & 9.428 & 9.513 \\
\hline
\end{tabular}
obtained. Hence, the results offer a guarantee in the accuracy of the current computational code to inspect the problem.

Table 1. Comparison of $\overline{N u}$ results for free convection of nanoliquids in a square box.

Table 2. Comparison of average Nusselt numbers for mixed convection in a lid-driven box.

\begin{tabular}{ccccccc}
\hline \multirow{2}{*}{ Gr } & \multicolumn{3}{c}{$\mathbf{R e}=\mathbf{4 0 0}$} & \multicolumn{3}{c}{$\operatorname{Re}=\mathbf{1 0 0 0}$} \\
\cline { 2 - 7 } & Present Work & Iwatsu et al. [37] & Sharif [36] & Present Work & Iwatsu et al. [37] & Sharif [36] \\
\hline $10^{2}$ & 4.09 & 3.84 & 4.05 & 6.48 & 6.33 & 6.55 \\
$10^{4}$ & 3.85 & 3.62 & 3.82 & 6.47 & 6.29 & 6.50 \\
$10^{6}$ & 1.10 & 1.22 & 1.17 & 1.66 & 1.77 & 1.81 \\
\hline
\end{tabular}




\section{Results and Discussion}

Numeric simulations are executed to examine the mixed convective stream and energy transfer of nanoliquids in a wall-driven enclosed box with thermal radiation and entropy generation. The average and cup mixing temperature and its RMSD values are also calculated. The calculations are carried out for a Richardson number $(R i)$ ranging from 0.01 to $10^{2}$, a volume fraction $(\phi)$ of nanoparticles from $0-4$ and a radiation parameter from 0 to 10 . The Grashof number is used as $10^{4}$ and the Reynolds number varies from 10 to $10^{3}$. The Prandtl number is taken as $\operatorname{Pr}=6.7$. The influence of convective stream and energy transport are assessed for several values of the volume fraction of nanoparticles, Richardson number, radiation parameter and the moving-wall directions. The results are depicted graphically for various combinations of parameters and the discussions are given below.

Figure 2 depicts the stream arrangement for several values of the pertinent parameters $\mathrm{Rd}$ and Ri for Case $1\left(U_{0}=+1\right)$ with $\Phi=0.02$. In Case 1 , wall is moving towards the right side, whereas the lid moves from the right-side to left-side in Case 2 . The moving-wall direction is very important and produces the shear force with the adjoining fluid along the upper portion of the box. Since the convective flow is driven by both the buoyant force and the shear stress due to the moving lid, the Richardson number clearly demonstrates the three regimes of convection (free, mixed and forced). The single clockwise rotating eddy appears in the forced convective regime $(\mathrm{Ri}<1)$ for all given values of the radiation parameter. Due to the strong shear force, the core area of the eddy travels towards the right-top corner of the enclosed box. When $\mathrm{Ri}=1$, that is, in the combined convective regime, the magnitude of both forces (shear and buoyancy) are comparable, the core region moving the center part of the portion of the enclosed box. In the buoyant convective regime, that is, $\mathrm{Ri}=100$, the variation on the flow pattern is clearly visible here. There is no change on the stream pattern in the forced convection regime when changing the radiation parameter. However, the evidence on the effect of the radiation parameter is clearly seen in the buoyancy convection regime upon raising the values of the radiation parameter for Case 1 .

Figure 3 exhibits the convective stream for several values of $\operatorname{Ri}$ and $\operatorname{Rd}$ for Case 2, with $\Phi=0.02$. The flow pattern is completely different from Case 1 . The dual cell gets for all values of $\mathrm{Ri}$ and $\mathrm{Rd}$ as it occupies the entire box. Since the shear force is dominant at $\mathrm{Ri}=0.01$, the core section of the eddy moves towards the left-top corner of the enclosed box. The counter acting eddy could not occupy the whole space as in Case 1, where the movement of liquid particles is aiding with the buoyant force. The buoyant force by the hot liquid along the hot wall produces the clockwise-rotating eddy along the hot wall. However, the shear force dominates here, the eddy by the moving-lid occupies most the box. When rising the Richardson number values to $\mathrm{Ri}=1$, the mixed convection exists, where both the shear and buoyancy forces are comparable, and the eddy produced by these forces occupies about half of the enclosure in the situation. The natural convection mode at $\mathrm{Ri}=100$ depicts different phenomena on the stream pattern compared to the other two modes. The eddy by the buoyancy force dominates and occupies most the enclosed box. It is also detected that the eddy by the shear force is weakened on raising the values of the radiation parameter. 
$\mathrm{Ri}=0.01$
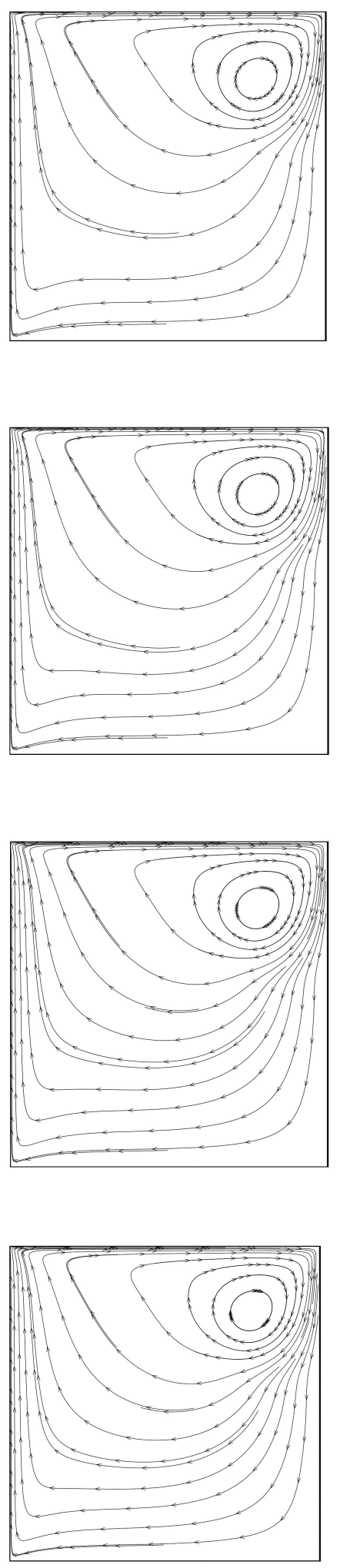

(d)

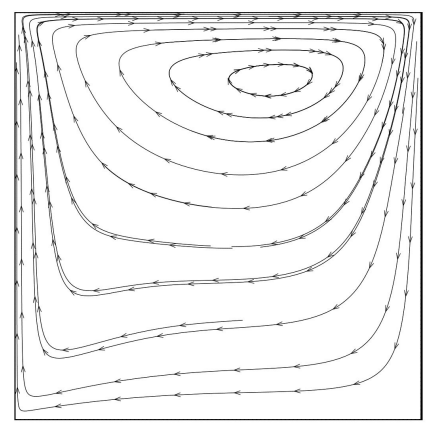

(a)

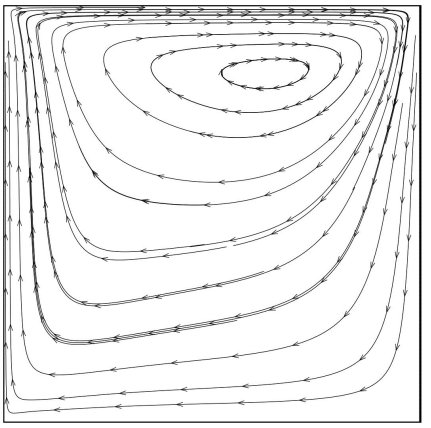

(b)

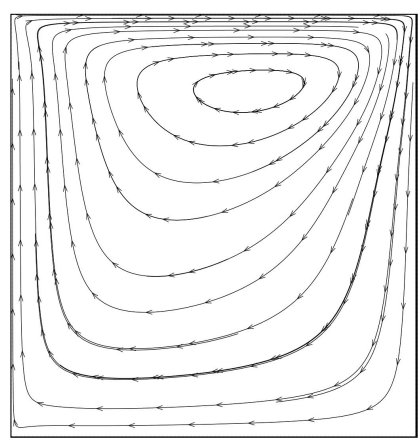

(c)
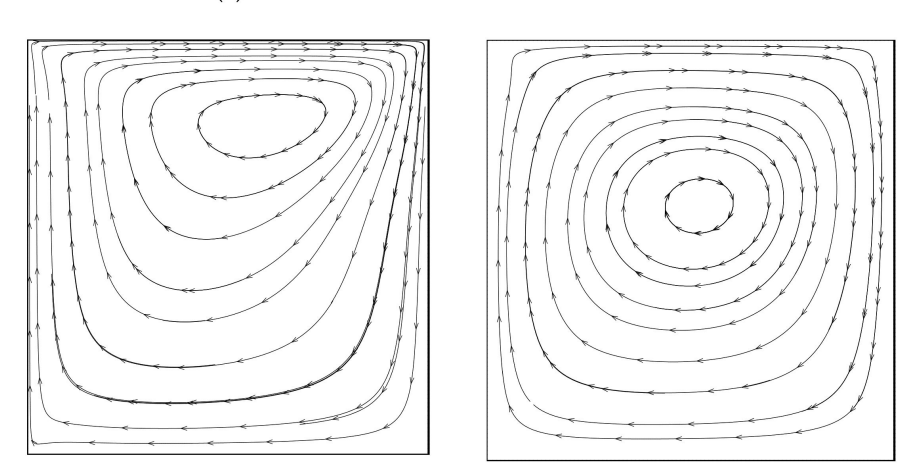

100
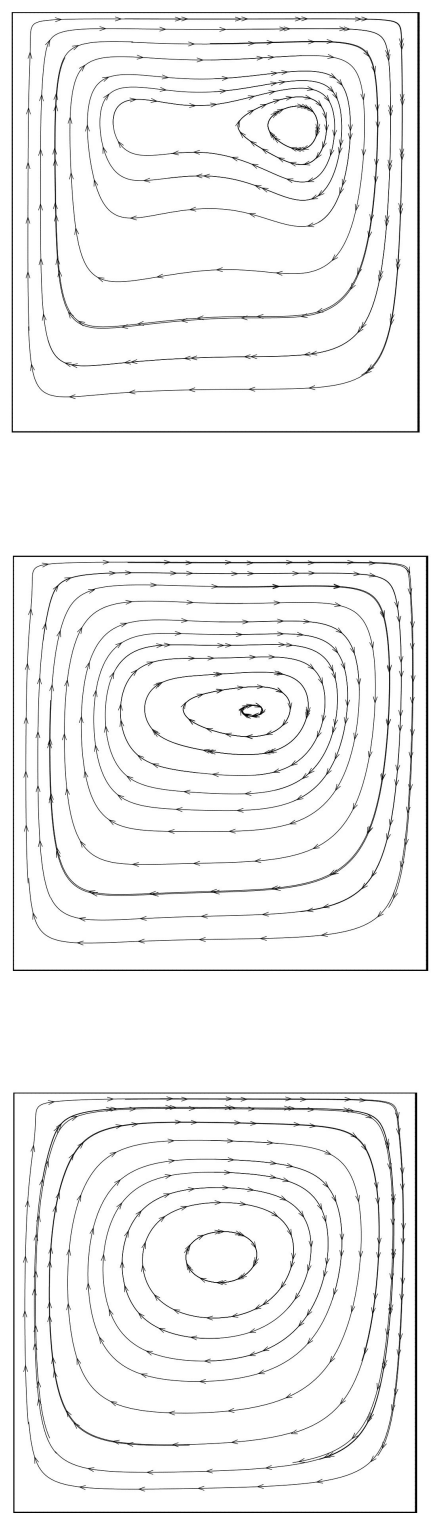

Figure 2. Streamlines for different $\mathrm{Rd}$ and Ri values with $\mathrm{U}_{0}=+1$ (Case 1$)$, and $\Phi=0.02$. (a) $\mathrm{Rd}=0$; (b) $\operatorname{Rd}=1 ;$ (c) $\operatorname{Rd}=5$; (d) $\operatorname{Rd}=10$. 
$\mathrm{Ri}=0.01$
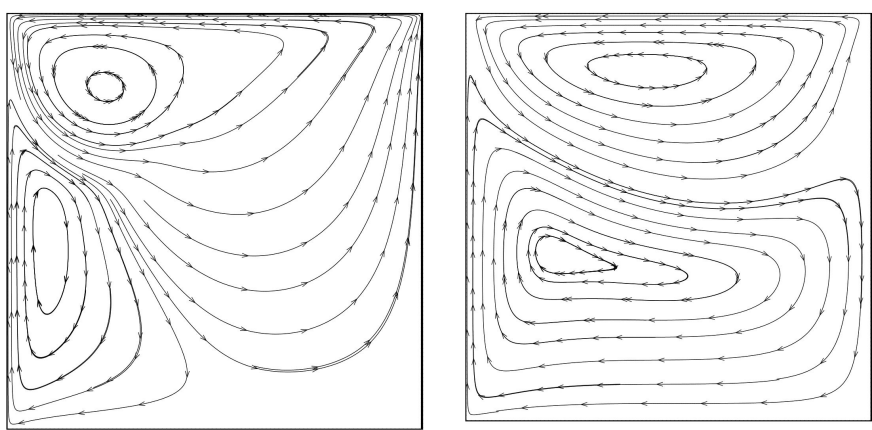

(a)
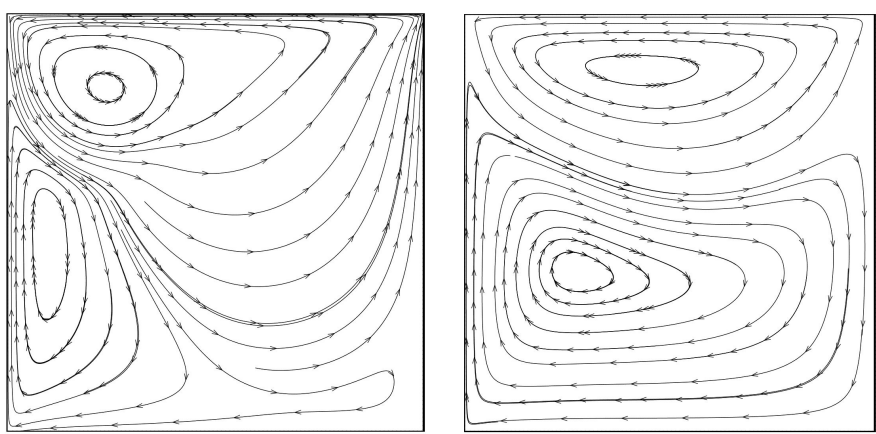

(b)
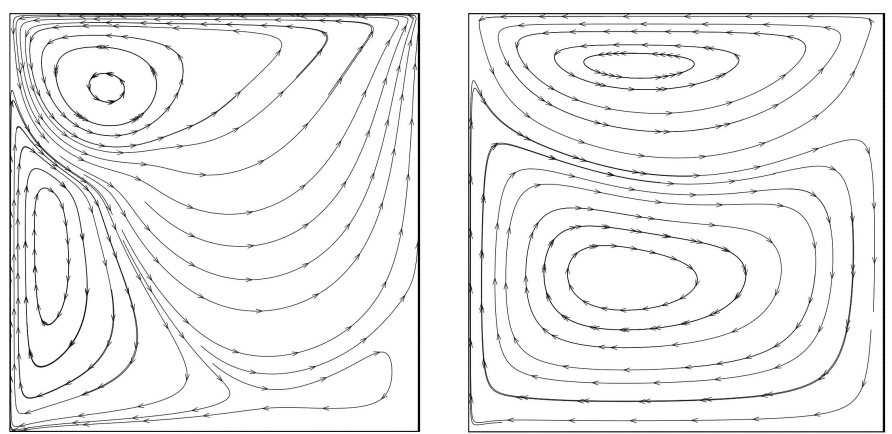

(c)
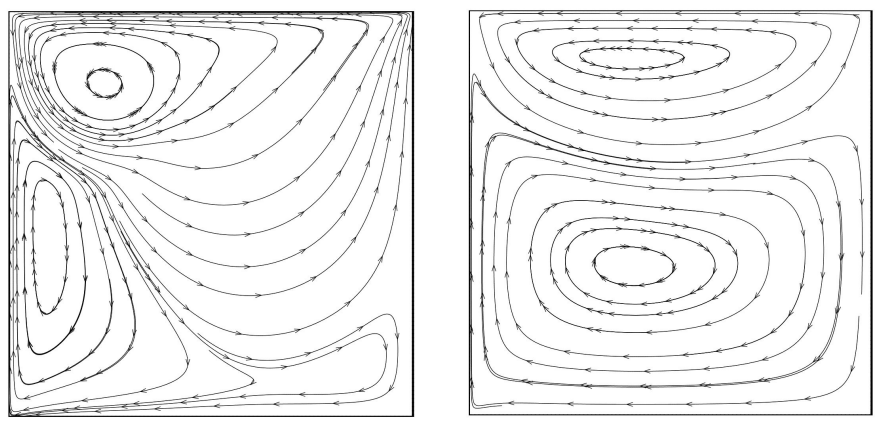

(d)

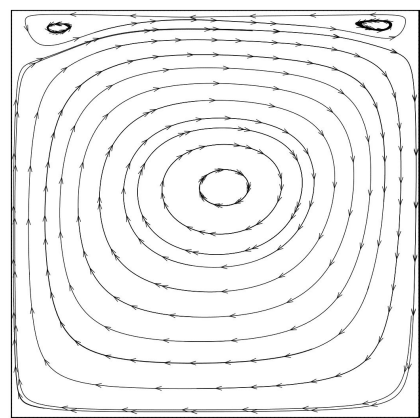

100
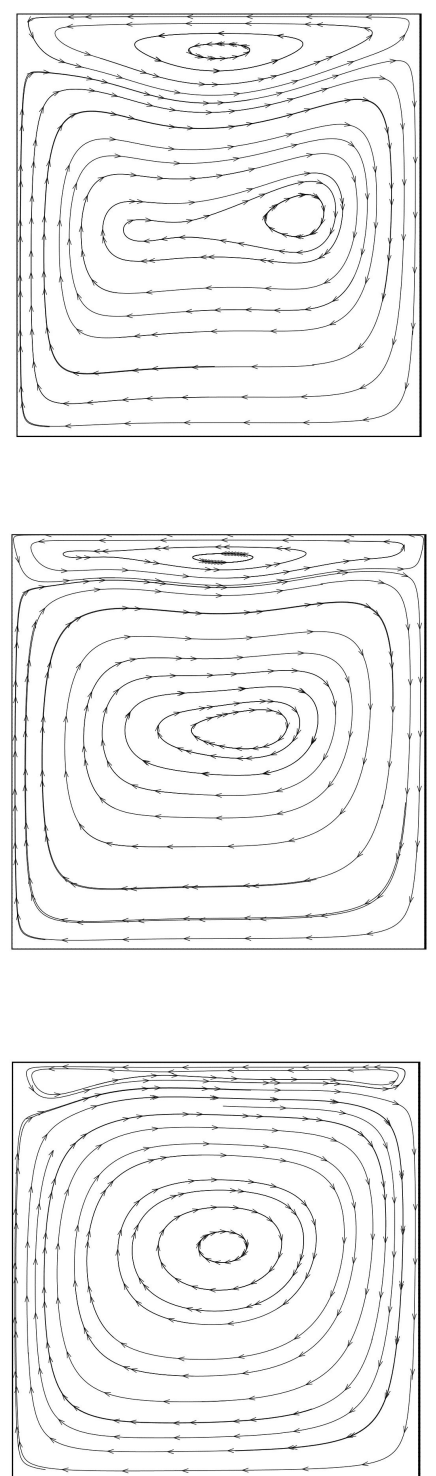

Figure 3. Streamlines for different $R d$ and $R i$ values with $U_{0}=-1$ (Case 2 ) and $\Phi=0.02$. (a) $R d=0$; (b) $\mathrm{Rd}=1 ;$ (c) $\mathrm{Rd}=5 ;$ (d) $\mathrm{Rd}=10$. 
Figure 4 depicts the thermal distribution for several values of the radiation parameter and the Richardson number for Case 1 with $\Phi=0.02$. The thermal boundary layers are shaped along the hot wall for all assumed values of the radiation parameter in the forced convection regime. The temperature boundary layers is weakened for higher values of the radiation $(R d=10)$ in the combined convection regime. The horizontal thermal stratification appears in the central region of the enclosed box in the absence of radiation or lower values of the radiation parameter for the natural convection regime. The temperature gradients near wall(s) disappear on rising the value of the radiation parameter. Figure 5 exhibits the isotherms for an opposite moving lid (Case 2) with the same parameters in Figure 4 . The thermal layers at the boundary do not appear along the hot wall in forced convection regime as in Case 1. Due to the dual cell structure in the flow field, the thermal layers at the boundary are collapsed along the hot wall in Case 2.

Figure 6 depicts the drag coefficient for several values of $\mathrm{Rd}$ and $\mathrm{Ri}$ for both cases of the moving lid directions. In Case 1, the skin friction declines upon raising the values of Ri. However, in Case 2, the skin friction behaves nonlinearly, that is, the skin friction grows up to Ri $=1$ and then it declines upon raising the values of Ri. It is detected that there is no change on the averaged skin friction for numerous values of $R d$ when $R i=0.01$ and $R i=0.1$, that is, in the forced convective regime. The skin friction declines upon rising the values of the radiation parameter in the combined and natural convective regimes.

Since the energy transport rate is a key factor in the thermal systems, the (average) energy transfer rate is depicted via the Nusselt number to explore the effect on various pertinent parameters. The local energy transport along the heated wall is computed by the local Nusselt number and it is depicted in Figure 7 for both cases of moving-wall directions. It is clearly exhibited from Figure $7 \mathrm{a}, \mathrm{c}, \mathrm{e}$ that the energy transport is diminished upon raising the values of the Richardson number for Case 1 . That is, the local energy transport along the hot wall is enhanced in the forced convective regime. It is almost thrice the value of local Nusselt number for free-convection regime. Case 2 also provides a similar trend on the energy transport upon raising the values of Ri number. It is detected that the local heat transport rises upon raising the radiation parameter for all convection regimes. The highest local energy transfer is observed at the bottom of the heated wall for Case 1 and then it decreases along the wall height. However, the highest local energy transfer is detected at the top of the heated wall for $\mathrm{Ri}=0.01$ and $\mathrm{Ri}=1$ in Case 2. However, the opposite trend is found for the free-convection regime in Case 2. The moving lid direction supports the fluid motion with the aiding of the buoyancy force. However, in Case 2, the moving lid direction suppresses the buoyancy force at the top section of the heated wall, and it results the dual cellular motion inside the enclosure. In the dual cell structure, the two cells hit at the top-left corner and provides the highest local heat energy transfer at this point, which is clearly seen from Figure $7 \mathrm{~b}$. The high amount of shear force has driven the heated fluid particles vigorously at this situation. Hence, the local heat energy transfer gives a similar trend in both cases for the natural convection regime. 

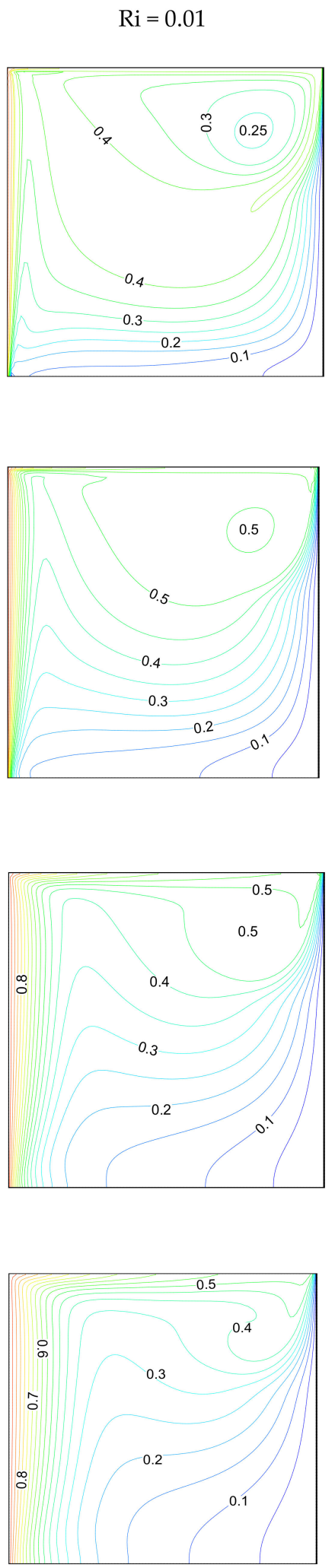

1

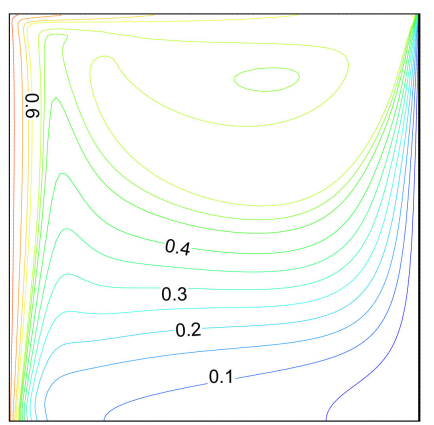

(a)

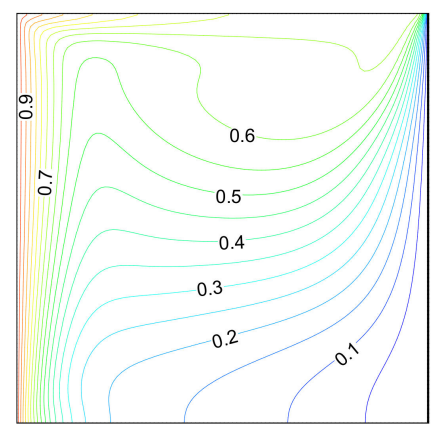

(b)

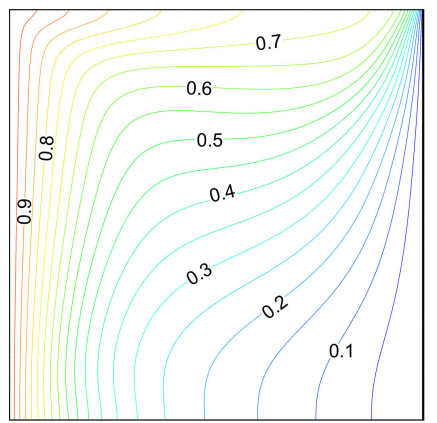

(c)
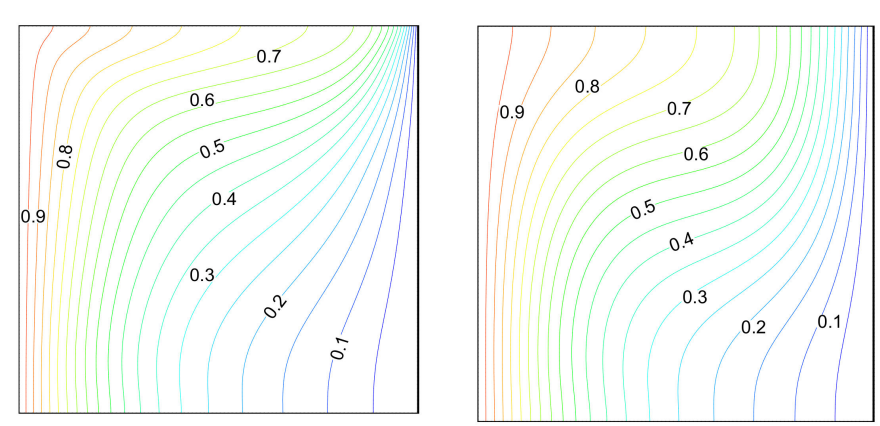

(d)

100
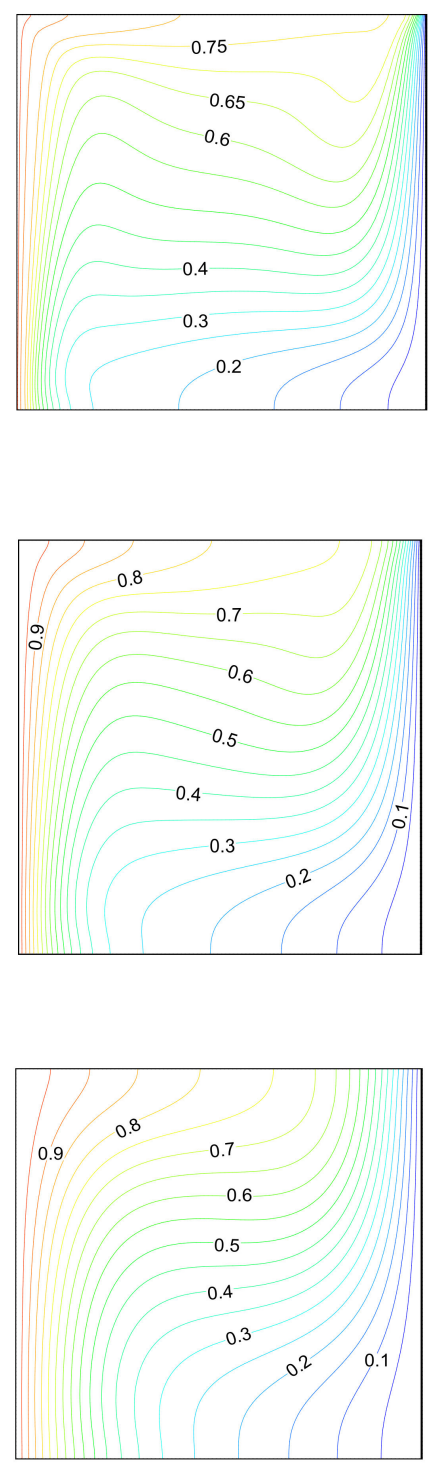

Figure 4. Isotherms for diverse $\mathrm{Rd}$ and $\mathrm{Ri}$ values with $\mathrm{U}_{0}=+1$ (Case 1 ) and $\Phi=0.02$. (a) $\mathrm{Rd}=0$; (b) $\operatorname{Rd}=1 ;(\mathbf{c}) \operatorname{Rd}=5 ;(d) \operatorname{Rd}=10$. 
$\mathrm{Ri}=0.01$
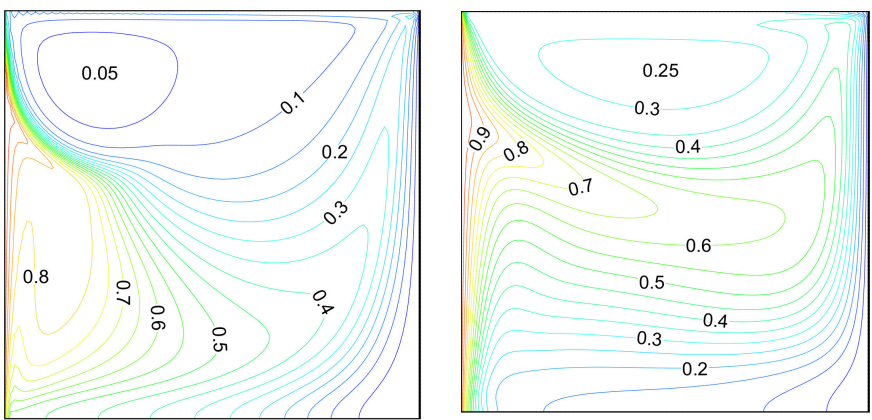

(a)
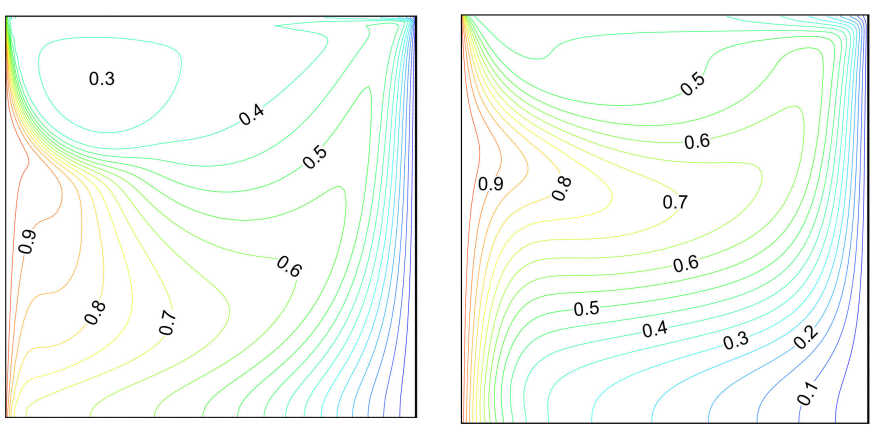

(b)
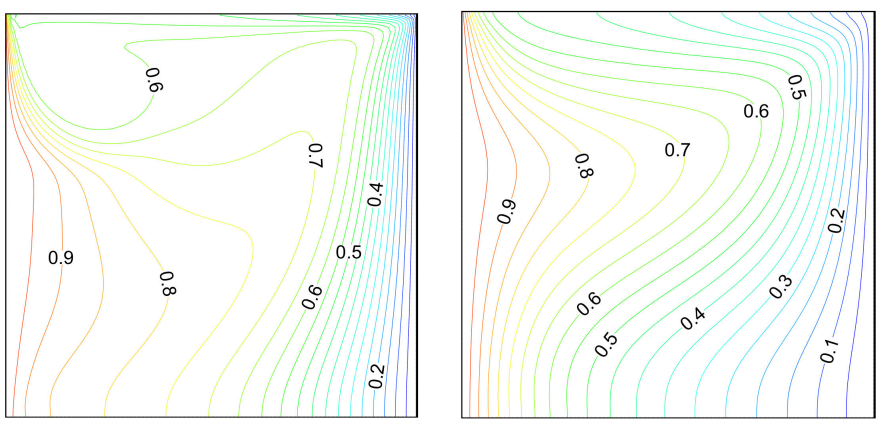

(c)
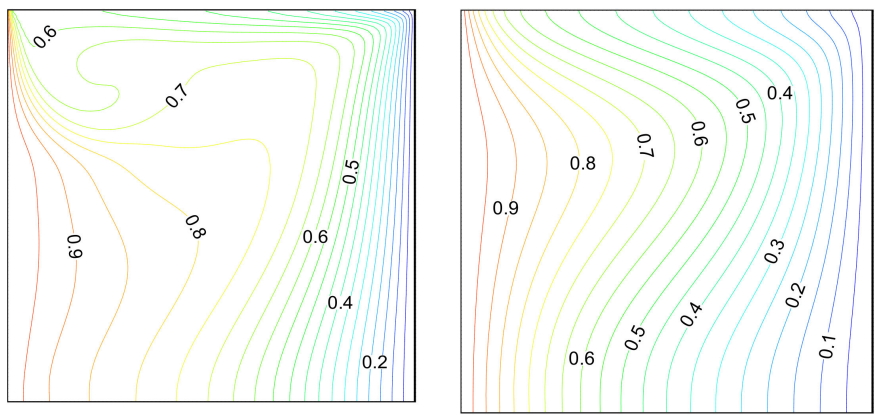

$\stackrel{9}{\circ}$

$0^{8}$

0.7

0.6

0.5

0.4

$0^{3}$

0.1

(d)

Figure 5. Isotherms for different $\mathrm{Rd}$ and $\mathrm{Ri}$ values with $\mathrm{U}_{0}=-1$ (Case 2 ) and $\Phi=0.02$. (a) $\mathrm{Rd}=0$; (b) $\mathrm{Rd}=1$; (c) $\mathrm{Rd}=5$; (d) $\mathrm{Rd}=10$. 


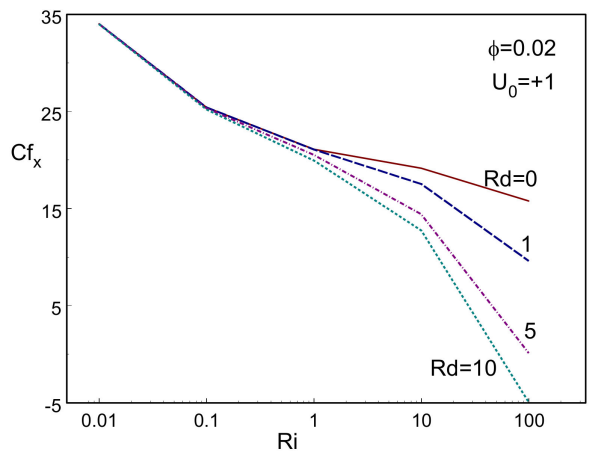

(a)

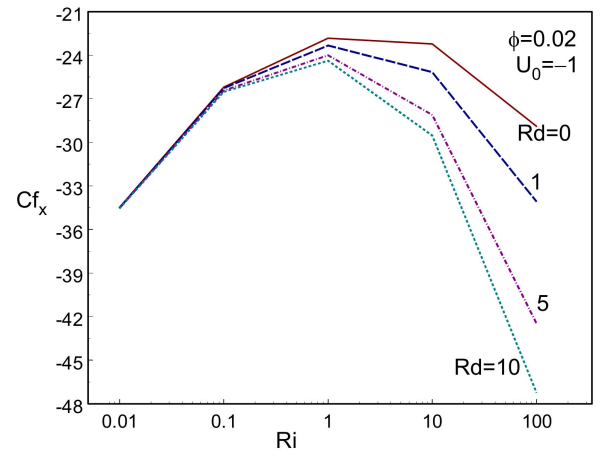

(b)

Figure 6. Drag coefficient versus Ri for different Rd. (a) Case 1; (b) Case 2.

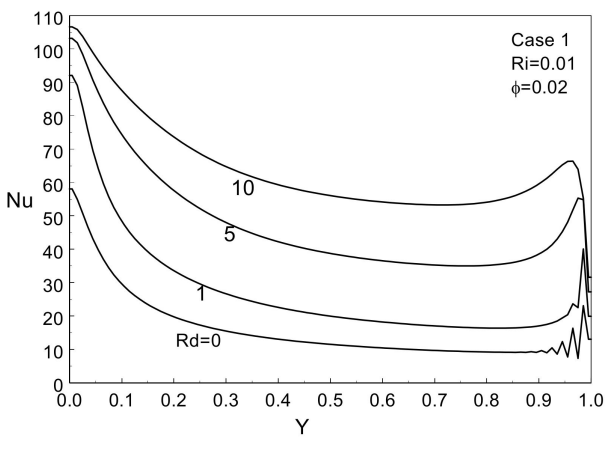

(a)

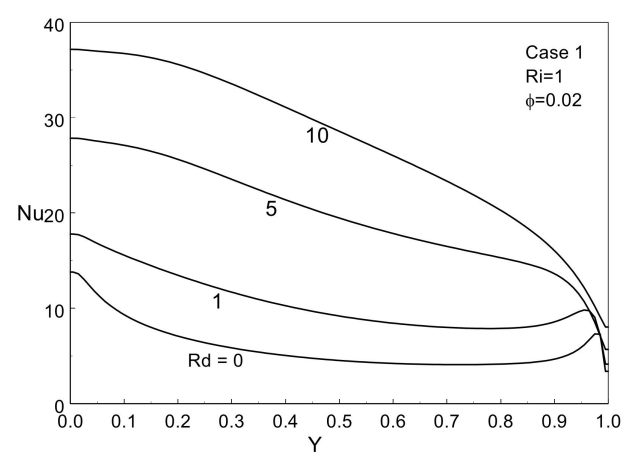

(c)

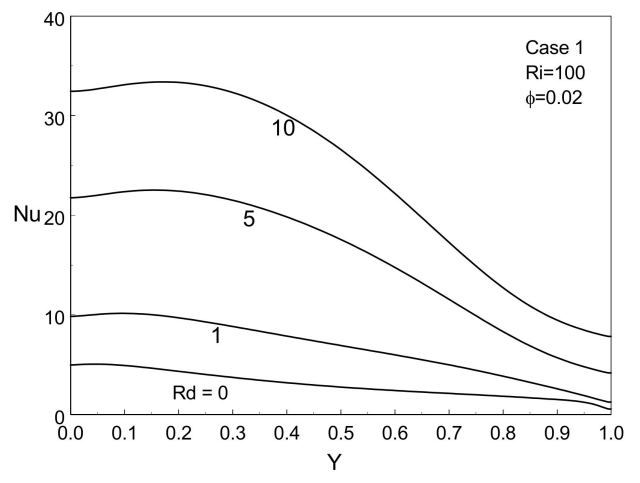

(e)

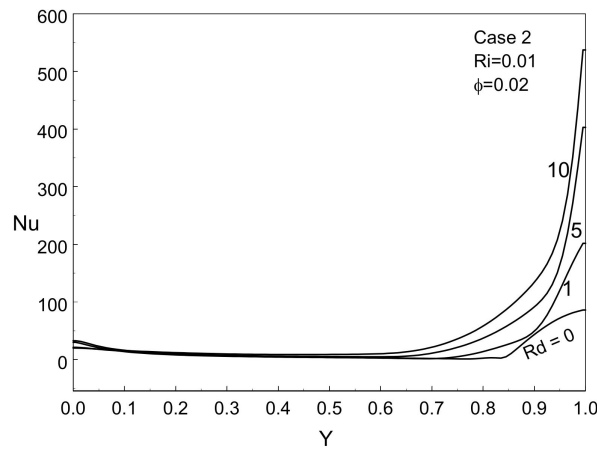

(b)

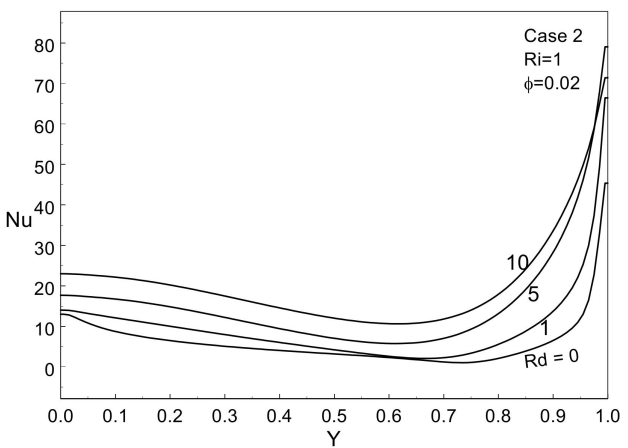

(d)

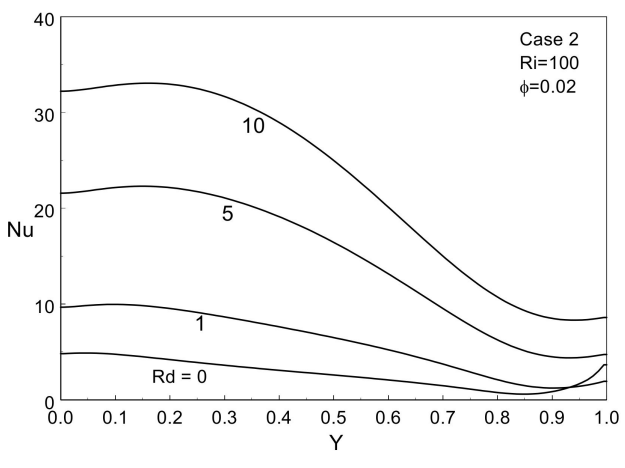

(f)

Figure 7. Local Nusselt number for diverse Ri and Rd. (a,c,e) Case 1; (b,d,f) Case 2. 
Figure 8 demonstrates the averaged Nusselt number for several values of Rd and Ri for Case 1 $\left(U_{0}=+1\right)$ and Case $2\left(U_{0}=-1\right)$. The averaged heat transport rate is enhanced upon raising the values of the radiation parameter for both cases of the moving-wall directions. It is detected that the averaged heat transfer declines upon raising the values of Ri. Further, scrutinizing these figures, it is found that the moving-wall direction affects the thermal energy transfer rate evidently. When the wall moves from the right-side to left-side (Case 2), the heat energy transfer rate is less due to the dual-eddy structure. The effect of nanometer sized particle volume fraction on the averaged energy transport is examined and it is portrayed in Figure 9a,b for several values of the Richardson number and two cases of moving-wall directions in the presence of radiation with $\mathrm{Rd}=5$. The averaged heat transport rate decreases upon raising the values of the nanoparticle volume fraction from $0 \% \sim 4 \%$ in mixed and free convective regimes for both moving-wall cases. But, the averaged heat transport rate rises with the nanoparticles volume fraction in Case 1 at $\mathrm{Ri}=0.01$. In Case 2 at $\mathrm{Ri}=0.01$, the averaged heat transfer increases first up to $\Phi=2 \%$ and then it decreases upon raising the value of $\Phi$. Comparing these two cases in Figure 9a,b, it is detected that the averaged Nusselt number is always high for Case 1 than that of Case 2. This is because of the dual eddy structure in Case 2. The energy transfer from the hotter region to the colder region taken by a single cell is faster than the energy transport by the two cells inside the enclosed box. Since the energy exchange between the two cells takes some time which slows down the overall energy transport within the enclosed box.

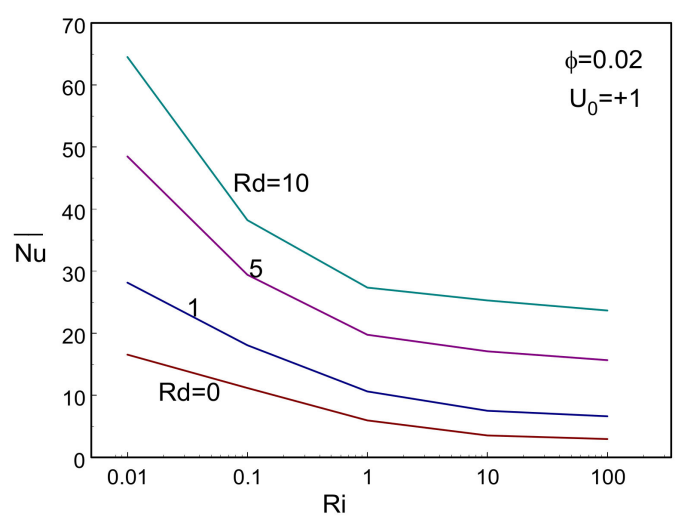

(a)

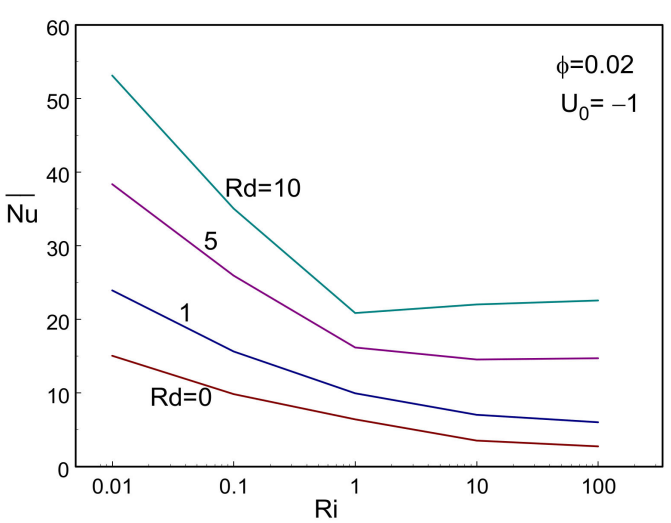

(b)

Figure 8. Averaged Nusselt number versus Ri for different Rd. (a) Case 1; (b) Case 2.

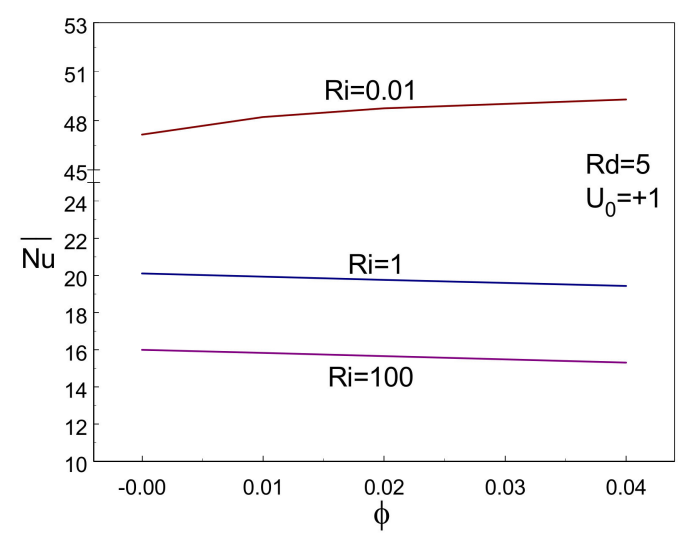

(a)

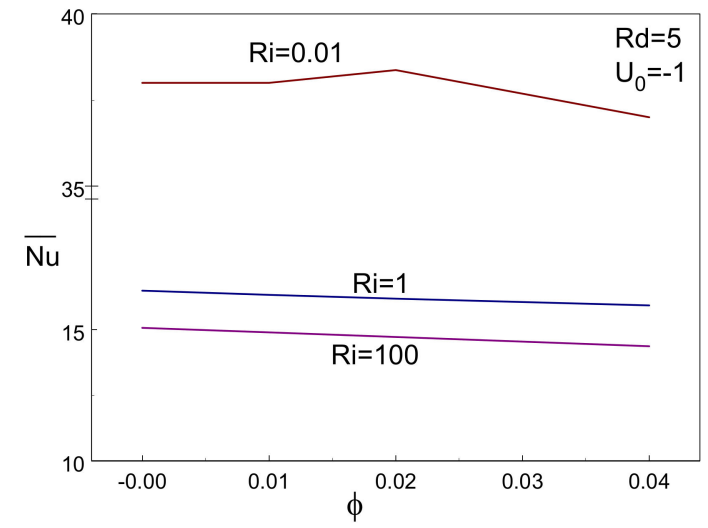

(b)

Figure 9. Averaged Nusselt number versus $\Phi$ for different Ri with Rd =5. (a) Case 1; (b) Case 2.

Figure 10 shows the increment level of the averaged energy transport for different radiation values compared with the absence of radiation parameter. The data clearly show the increasing level of 
averaged energy transport while raising the values of $\mathrm{Rd}$ in both cases of moving wall. The increment level is very high in the natural convection regime in both cases. Figure 11 demonstrates the cup-mixing temperature for various values of $\mathrm{Ri}$ and $\mathrm{Rd}$ parameters. The behavior of cup-mixing temperature is nonlinear fashion for Case 1, however, Case 2 shows almost a linear fashion. The deviation in cup-mixing temperature with $\mathrm{Rd}$ is high at forced convection regime for Case 2 . However, it is almost same in free-convection case. The $\mathrm{T}_{\text {cup }}$ values are almost constant when changing the values of Rd in free-convection flow for Case 2. Figure 12 demonstrates the average temperature for different $\mathrm{Ri}$ and $\mathrm{Rd}$ values. The higher $\mathrm{T}_{\text {cup }}$ values indicates the well mixing of fluid with higher temperature. It is obviously seen from Figure 12 that the $\mathrm{T}_{\mathrm{avg}}$ is almost constant for all values of $\mathrm{Rd}$ in free-convection regime. The maxima of $\mathrm{T}_{\text {avg }}$ attains at $\mathrm{Ri}=100$ for all $\mathrm{Rd}$ values in Case 1, see Figure 12a. From Figure 12b, we observe that the deviation of $\mathrm{T}_{\mathrm{avg}}$ is high at $\mathrm{Ri}=0.01$ in Case 2.

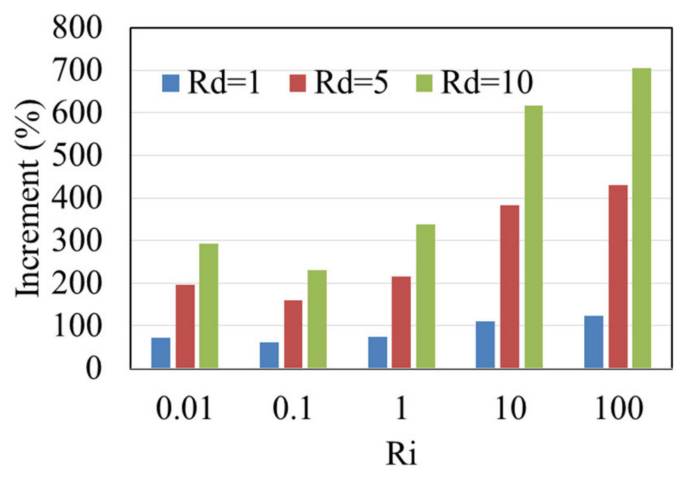

(a)

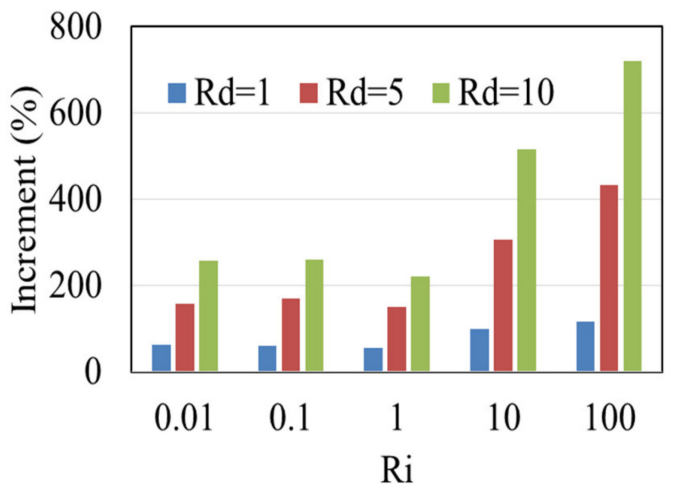

(b)

Figure 10. Increment of averaged Nusselt number. (a) Case 1; (b) Case 2.

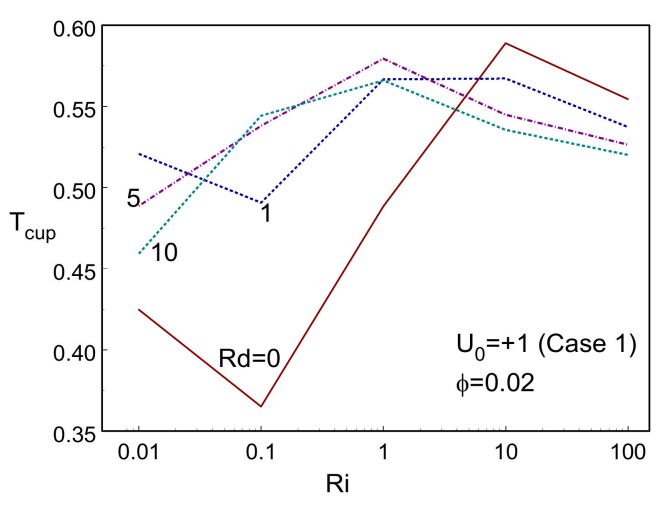

(a)

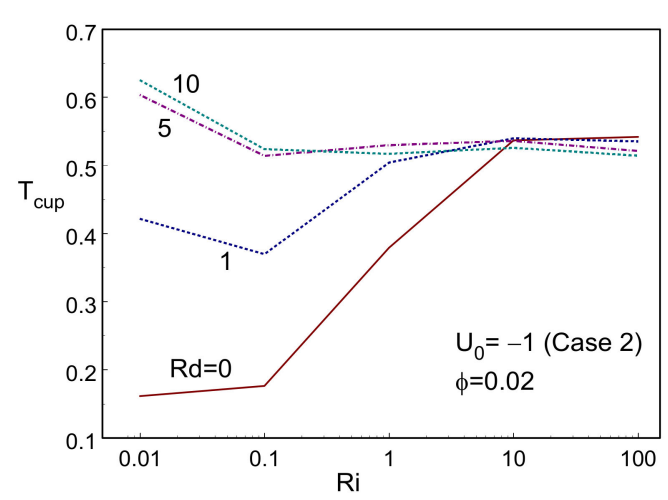

(b)

Figure 11. Cup-mixing temperature for different Ri and Rd values. (a) Case 1; (b) Case 2.

Figures 13 and 14 portray the RMSD Tcup $_{\text {and }}$ RMSD $D_{\text {Tavg }}$ for both cases with different Ri and Rd values. Since the nondimensional temperature varies between 0 and 1, the RMSD values are below 1 in the present examination. It is noticed from Figure 13 a that the $\mathrm{RMSD}_{\text {Tcup }}$ increases first and decreases on raising the Ri values for Case 1. The opposite trend is observed for Case 2 in the absence of thermal radiation. However, $\mathrm{RMSD}_{\text {Tcup }}$ increases linearly with $\mathrm{Ri}$ for $\mathrm{Rd} \geq 5$ for Case 2 . It is observed from

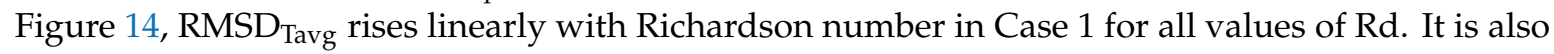

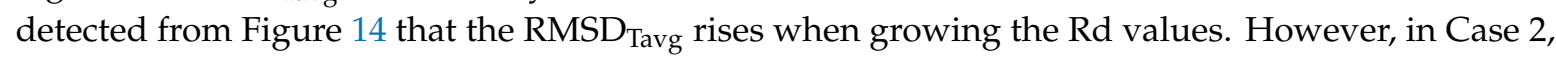
it behaves nonlinearly for either absence of $\mathrm{Rd}$ or low values of $\mathrm{Rd}$. However, it acts as same as Case 1

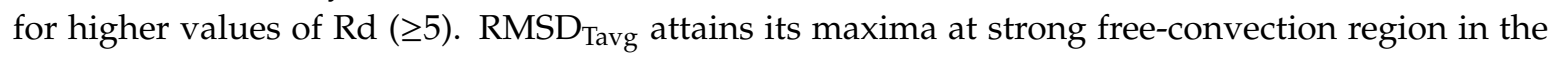
presence of thermal radiation. Since the RMSD values are lower in all cases, we get higher temperature uniformity inside the box. 


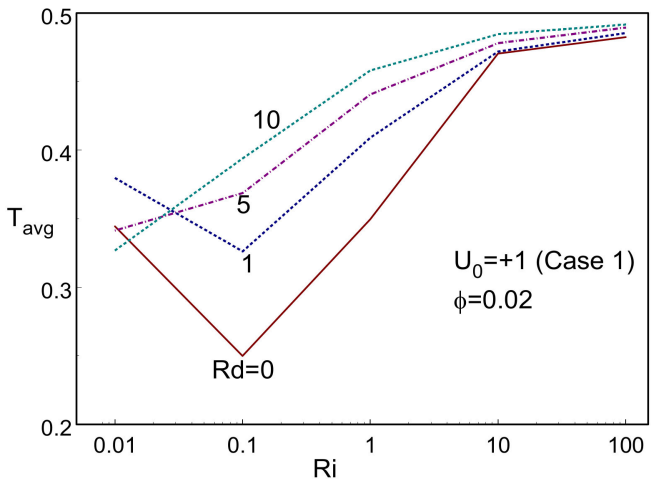

(a)

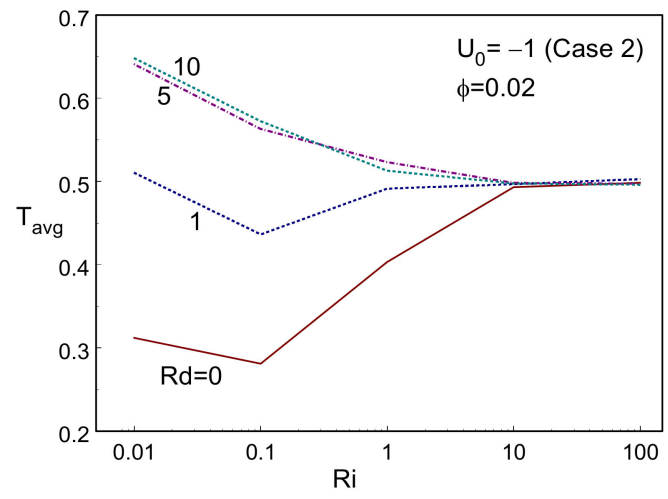

(b)

Figure 12. Averaged temperature for different Ri and Rd values. (a) Case 1; (b) Case 2.

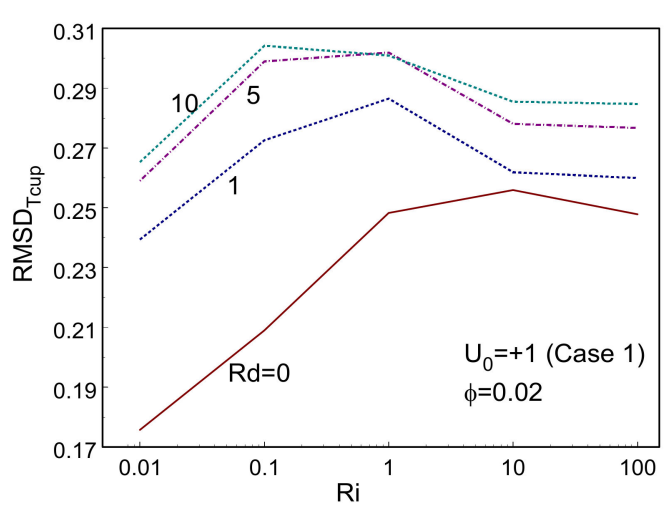

(a)

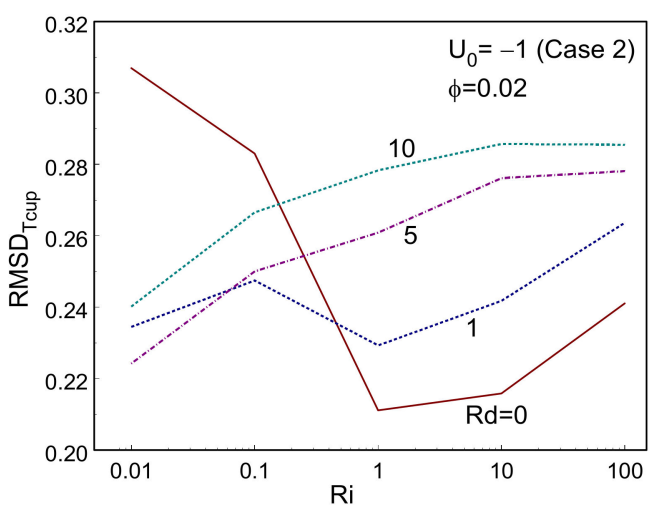

(b)

Figure 13. RMSD ${ }_{\text {Tcup }}$ for different Ri and Rd values. (a) Case 1; (b) Case 2.

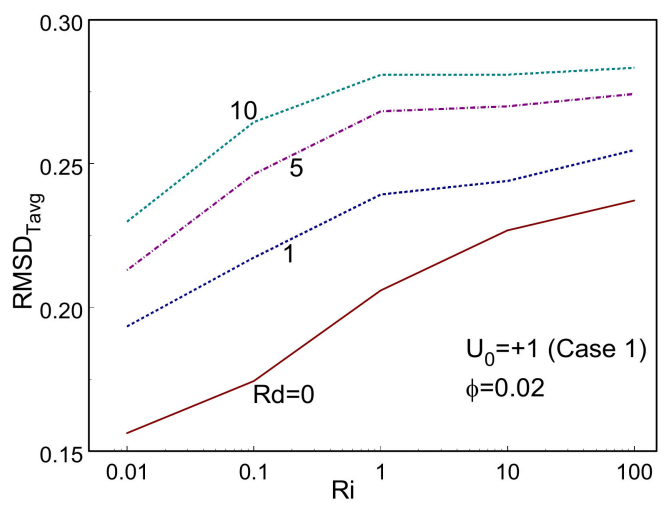

(a)

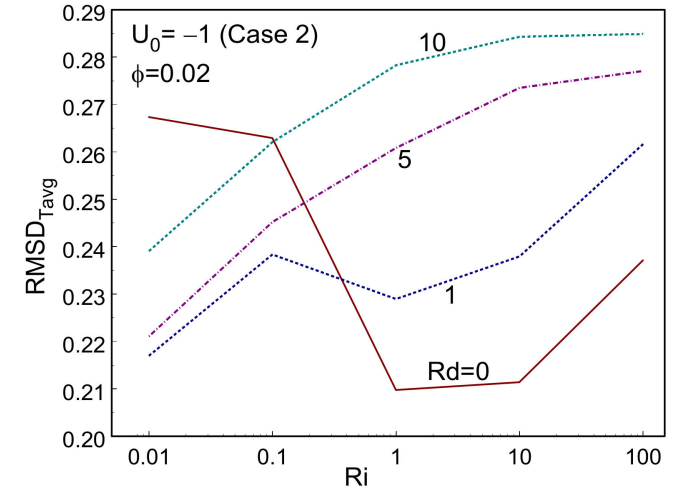

(b)

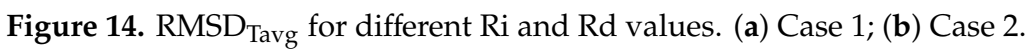

Figure 15 portrays the influence of Bejan number for both cases with different Ri and Rd values. The values of Be are almost constant on raising the $\mathrm{Ri}$ values until $\mathrm{Ri}=10$, but, after this, it suddenly fall down at $\mathrm{Ri}=100$ for both direction of moving-wall. When raising the $\mathrm{Rd}$ values, the Bejan number is increased. It results that the radiation parameter boosted up the entropy generation inside the box. It is clear that Be lies between 0 and 1 . If Be tends to 0 then the irreversibility due to fluid friction controls. If Be tends to 1 , the irreversibility due to thermal transfer is leading. In all cases, the values of Be is tends to 1 , it results that the irreversibility due to thermal transfer is dominant here. 


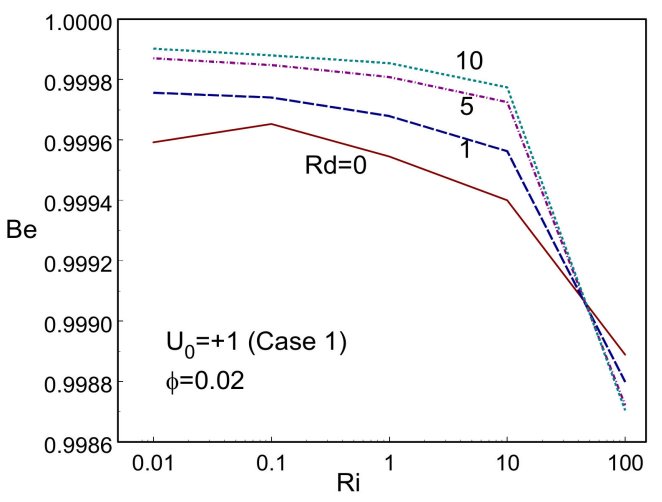

(a)

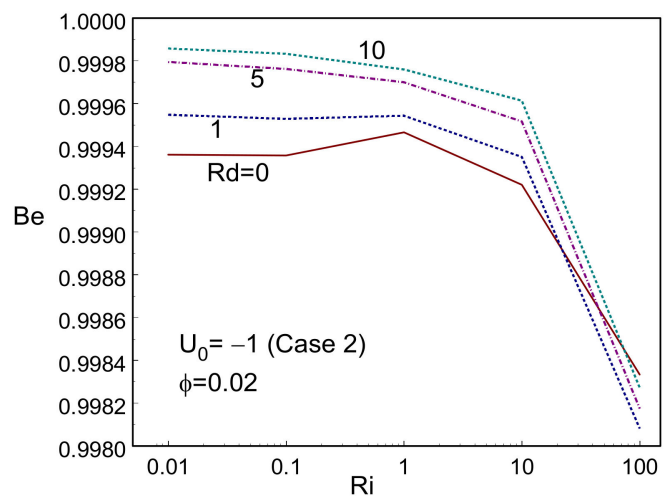

(b)

Figure 15. Bejan number for different Ri and Rd values. (a) Case 1; (b) Case 2.

\section{Conclusions}

The impacts of the direction of a moving wall, thermal radiation and entropy on combined convective stream and energy transfer of nanoliquids in a lid-driven enclosed box is numerically explored. The leading mathematical model is solved by the control volume technique. The following remarkable discoveries are detected from the study:

The moving-wall direction drastically affects the stream field inside the enclosure. Single and dual cell structures are formed in Case 1 and Case 2, respectively for all values of Ri, radiation parameter and all nanoliquids;

- The skin friction declines upon raising the values of the Richardson number for Case 1. It increases up to $\mathrm{Ri}=1$ and then decreases upon raising the Richardson number in Case 2;

- The higher local energy transport is attained at bottom of the heat wall for Case 1 and at top of the hot wall for Case 2 in the forced and mixed convective flow regimes. The free-convection mode provides a similar trend on both cases, that is, the highest heat transfer attains near the bottom of the barrier;

$0 \quad$ The thermal radiation parameter enhances the energy transport across the enclosure for all given values of Ri and $\phi$ in both directions of the moving wall;

$\bigcirc \quad$ The moving-wall direction greatly influences the energy transfer rate. The Case 1 (moving-wall from left to right) provides a higher heat transfer rate than that of Case 2 for all values of Ri and the radiation parameter;

- The averaged heat transport declines upon rising the volume fraction of nanoparticle in free and mixed convection regimes for both moving-wall directions. The averaged heat transport increases with the nanoparticles volume fraction in Case 1. It rises first and then declines upon raising the values of nanoparticles volume fraction in Case 2;

$\bigcirc \quad$ The Bejan number enhances on raising the Rd values. Entropy generation dominates by thermal transfer;

- The lower values of RMSD in all cases illustrates the higher temperature uniformity inside the box;

$\bigcirc \quad$ The $\mathrm{T}_{\text {cup }}$ and $\mathrm{T}_{\text {avg }}$ values are almost constant when changing the values of $\mathrm{Rd}$ in free-convection flow for Case 2. The cup-mixing temperature behaves non-linear fashion for Case 1 and almost a linear fashion for Case 2.

Author Contributions: Conceptualization, S.S.; methodology, S.S.; software, S.S.; validation, S.S.; formal analysis, S.S.; investigation, S.S.; writing-original draft preparation, S.S.; writing-review and editing, S.S. and A.J.C.; visualization, S.S.; supervision, S.S.; project administration, S.S.; funding acquisition, S.S.; F.O.M.M.; M.S.A. and A.M.A. All authors have read and agreed to the published version of the manuscript. 
Funding: This project was funded by the research and development office (RDO), at the Ministry of Education, Kingdom of Saudi Arabia, under Grant No. (H1Q1-40-2019).

Acknowledgments: This project was funded by the research and development office (RDO), at the Ministry of Education, Kingdom of Saudi Arabia, under Grant No. (H1Q1-40-2019). The authors also acknowledge with thanks research and development office (RDO-KAU) at King Abdulaziz University for technical support.

Conflicts of Interest: The authors declare no conflict of interest.

\section{References}

1. Alsabery, A.I.; Tayebi, T.; Roslan, R.; Chamkha, A.J.; Hashim, I. Entropy Generation and Mixed Convection Flow Inside a Wavy-Walled Enclosure Containing a Rotating Solid Cylinder and a Heat Source. Entropy 2020, 22, 606. [CrossRef]

2. Chamkha, A.J.; Selimefendigil, F.; Oztop, H.F. MHD mixed convection and entropy generation in a lid-driven triangular cavity for various electrical conductivity models. Entropy 2018, 20, 903. [CrossRef]

3. Bhuvaneswari, M.; Sivasankaran, S.; Kim, Y.J. Numerical Study on double diffusive mixed convection in a two-sided lid driven cavity with Soret effect. Numer. Heat Transf. Part A 2011, 59, 543-560. [CrossRef]

4. Sivasankaran, S.; Cheong, H.T.; Bhuvaneswari, M.; Ganesan, P. Effect of moving wall direction on mixed convection in an inclined lid-driven square cavity with sinusoidal heating. Numer. Heat Transf. Part A 2016, 69, 630-642. [CrossRef]

5. Mahmoudinezhad, S.; Rezania, A.; Yousefi, T. Adiabatic partition effect on natural convection heat transfer inside a square cavity: Experimental and numerical studies. Heat Mass Transf. 2018, 54, 291-304. [CrossRef]

6. Selimefendigil, F.; Öztop, H.F.; Chamkha, A.J. Analysis of mixed convection of nanofluid in a 3D lid-driven trapezoidal cavity with flexible side surfaces and inner cylinder. Int. Commun. Heat Mass Transf. 2017, 87, 40-51. [CrossRef]

7. Oztop, H.F.; Almeshaal, M.A.; Kolsi, L.; Rashidi, M.M.; Ali, M.E. Natural convection and irreversibility evaluation in a cubic cavity with partial opening in both top and bottom sides. Entropy 2019, 21, 116. [CrossRef]

8. Safaei, M.R.; Shadloo, M.S.; Goodarzi, M.S.; Hadjadj, A.; Goshayeshi, H.R.; Afrand, M.; Kazi, S.N. A survey on experimental and numerical studies of convection heat transfer of nanofluids inside closed conduits. Adv. Mech. Eng. 2016, 8, 1687814016673569. [CrossRef]

9. Chamkha, A.J.; Selimefendigil, F. MHD free convection and entropy generation in a corrugated cavity filled with a porous medium saturated with nanofluids. Entropy 2018, 20, 846. [CrossRef]

10. Sivasankaran, S.; Sivakumar, V.; Hussein, A.K. Numerical study on mixed convection in an inclined lid-driven cavity with discrete heating. Int. Commun. Heat Mass Transf. 2013, 46, 112-125. [CrossRef]

11. Sivasankaran, S.; Pan, K.L. Lattice Boltzmann simulation for a lid-driven cavity with discrete heating/cooling sources. AIAA J. Thermophys. Heat Transf. 2016, 30, 573-586. [CrossRef]

12. Mekroussi, S.; Nehari, D.; Bouzit, M.; Chemloul, N.E.S. Analysis of mixed convection in an inclined lid-driven cavity with a wavy wall. J. Mech. Sci. Technol. 2013, 27, 2181-2190. [CrossRef]

13. Sivakumar, V.; Sivasankaran, S. Mixed convection in an inclined lid-driven cavity with non-uniform heating on both sidewalls. J. Appl. Mech. Tech. Phys. 2014, 55, 634-649. [CrossRef]

14. Sivasankaran, S.; Ananthan, S.S.; Abdul Hakeem, A.K. Mixed convection in a lid-driven cavity with sinusoidal boundary temperature at the bottom wall in the presence of magnetic field. Sci. Iran. Trans. B Mech. Eng. 2016, 23, 1027-1036. [CrossRef]

15. Sivasankaran, S.; Ananthan, S.S.; Bhuvaneswari, M.; Abdul Hakeem, A.K. Double-diffusive mixed convection in a lid-driven cavity with non-uniform heating on sidewalls. Sadhana 2017, 42, 1929-1941. [CrossRef]

16. Kasmani, R.M.D.; Sivasankaran, S.; Bhuvaneswari, M.; Hussein, A.K. Analytical and numerical study on convection of nanofluid past a moving wedge with Soret and Dufour effects. Int. J. Numer. Methods Heat Fluid Flow 2017, 27, 2333-2354. [CrossRef]

17. Öztop, H.F.; Sakhrieh, A.; Abu-Nada, E.; Al-Salem, K. Mixed convection of MHD flow in nanofluid filled and partially heated wavy walled lid-driven enclosure. Int. Commun. Heat Mass Transf. 2017, 86, 42-51. [CrossRef]

18. Rashidi, M.M.; Nasiri, M.; Shadloo, M.S.; Yang, Z. Entropy Generation in a Circular Tube Heat Exchanger Using Nanofluids: Effects of Different Modeling Approaches. Heat Transf. Eng. 2017, 38, 853-866. [CrossRef] 
19. Sivasankaran, S.; Narrein, K. Numerical investigation of two-phase laminar pulsating nanofluid flow in helical microchannel filled with a porous medium. Int. Commun. Heat Mass Transf. 2016, 75, 86-91. [CrossRef]

20. Khashi'ie, N.S.; Md Arifin, N.; Pop, I. Mixed convective stagnation point flow towards a vertical riga plate in hybrid $\mathrm{Cu}-\mathrm{Al}_{2} \mathrm{O}_{3} /$ water nanofluid. Mathematics 2020, 8, 912. [CrossRef]

21. Sheremet, M.A.; Grosan, T.; Pop, I. Natural convection and entropy generation in a square cavity with variable temperature side walls filled with a nanofluid: Buongiorno's mathematical model. Entropy 2017, $19,337$. [CrossRef]

22. Alsabery, A.I.; Ismael, M.A.; Chamkha, A.J.; Hashim, I. Numerical investigation of mixed convection and entropy generation in a wavy-walled cavity filled with nanofluid and involving a rotating cylinder. Entropy 2018, 20, 664. [CrossRef]

23. Santra, A.K.; Sen, S.; Chakraborty, N. Study of heat transfer augmentation in a differentially heated square cavity using copper-water nanofluid. Int. J. Therm. Sci. 2008, 47, 1113-1122. [CrossRef]

24. Abu-Nada, E.; Oztop, H.F. Effects of inclination angle on natural convection in enclosures filled with Cu-water nanofluid. Int. J. Heat Fluid Flow 2009, 30, 669-678. [CrossRef]

25. Ghasemi, B.; Aminossadati, S.M. Natural convection heat transfer in an inclined enclosure filled with a water $\mathrm{CuO}$ nanofluid. Numer. Heat Transf. Part A 2009, 55, 807-823. [CrossRef]

26. Bhuvaneswari, M.; Ganesan, P.; Sivasankaran, S.; Viswanathan, K.K. Effect of variable fluid properties on natural convection of nanofluids in a cavity with linearly varying wall temperature. Math. Probl. Eng. 2015, 2015, 391786. [CrossRef]

27. Sivasankaran, S.; Mansour, M.A.; Rashad, A.M.; Bhuvaneswari, M. MHD mixed convection of Cu-water nanofluid in a two-sided lid-driven porous cavity with a partial slip. Numer. Heat Transf. Part A 2016, 70, 1356-1370. [CrossRef]

28. Rashad, A.M.; Sivasankaran, S.; Mansour, M.A.; Bhuvaneswari, M. Magneto-convection of nanofluids in a lid-driven trapezoidal cavity with internal heat generation and discrete heating. Numer. Heat Transf. Part A 2017, 71, 1223-1234. [CrossRef]

29. Mansour, M.A.; Abd El-Aziz, M.M.; Mohamed, R.A.; Ahmed, S.E. Numerical simulation of natural convection in wavy porous cavities under the influence of thermal radiation using a thermal non-equilibrium model. Transp. Porous Media 2011, 86, 585-600. [CrossRef]

30. Moufekkir, F.; Moussaoui, M.A.; Mezrhab, A.; Bouzidi, M.; Lemonnier, D. Combined double diffusive convection and radiation in a square enclosure filled with semitransparent fluid. Comput. Fluids 2012, 69, 172-178. [CrossRef]

31. Mahapatra, T.R.; Pal, D.; Mondal, S. Mixed convection flow in an inclined enclosure under magnetic field with thermal radiation and heat generation. Int. Commun. Heat Mass. Transf. 2013, 41, 47-56. [CrossRef]

32. Saleem, M.; Hossain, M.A.; Saha, S.C.; Gu, Y.T. Heat transfer analysis of viscous incompressible fluid by combined natural convection and radiation in an open cavity. Math. Probl. Eng. 2014, 2014, 412480. [CrossRef]

33. Zhang, J.K.; Li, B.W.; Dong, H.; Luo, X.H.; Lin, H. Analysis of magnetohydrodynamics (MHD) natural convection in 2D cavity and 3D cavity with thermal radiation effects. Int. J. Heat Mass. Transf. 2017, 112, 216-223. [CrossRef]

34. Alzahrani, A.K.; Sivasankaran, S.; Bhuvaneswari, M. Numerical Simulation on Convection and Thermal Radiation of Casson Fluid in an Enclosure with Entropy Generation. Entropy 2020, 22, 229. [CrossRef]

35. Ho, C.J.; Chen, M.W.; Li, Z.W. Numerical simulation of natural convection of nanofluid in a square enclosure: Effects due to uncertainties of viscosity and thermal conductivity. Int. J. Heat Mass. Transf. 2008, 51, 4506-4516. [CrossRef]

36. Sharif, M.A.R. Laminar mixed convection in shallow inclined driven cavities with hot moving lid on top and cooled from bottom. Appl. Therm. Eng. 2007, 27, 1036-1042. [CrossRef]

37. Iwatsu, R.; Hyun, J.M.; Kuwahara, K. Mixed convection in a driven cavity with a stable vertical temperature gradient. Int. J. Heat Mass. Transf. 1993, 36, 1601-1608. [CrossRef]

(C) 2020 by the authors. Licensee MDPI, Basel, Switzerland. This article is an open access article distributed under the terms and conditions of the Creative Commons Attribution (CC BY) license (http://creativecommons.org/licenses/by/4.0/). 